\title{
ERBB2 Amplification Status
}

National Cancer Institute

\section{Source}

National Cancer Institute. ERBB2 Amplification Status. NCI Thesaurus. Code C157249.

A procedure used to detect amplifications involving all or part of the ERBB2 gene. 